\title{
Assessing and managing cyanobacterial risks in water-use systems
}

\author{
Ingrid Chorus and Rory Moses McKeown
}

\section{CONTENTS}

Introduction

6.1 Levels for exerting control over cyanotoxin occurrence and exposure

6.2 Water safety planning as a framework for assessing and managing cyanobacterial risks

6.2.1 Getting ready for assessment and planning: forming the team

6.2.2 Describing the water-use system and its users

6.2.2.1 Identifying water users and uses (including sensitive subpopulations)

6.2.3 Assessing the risk of cyanotoxin occurrence and the system's efficacy in controlling it

6.2.3.1 Coping with uncertainty

6.2.3.2 Cyanotoxin risks in relation to other public health risks from exposure to water

6.2.4 Improvement planning: choosing additional cyanotoxin control measures for system improvement

6.2.5 Monitoring the functioning of control measures for cyanotoxin management and developing a management plan

6.2.6 Verifying that exposure is sufficiently avoided and water quality targets are achieved

6.2.7 Documenting the planning process and outcomes

6.2.7.1 Documenting management procedures

6.2.8 Developing supporting programmes

6.2.9 Periodic review and revision 


\section{INTRODUCTION}

Cyanotoxin occurrence in water to which people may be exposed depends on the extent to which conditions in the respective waterbody favour the proliferation of cyanobacteria. Where barriers (or "control measures") are in place (e.g., natural, as well as technical treatment or engineered barriers), as well as managerial and planning measures, human exposure will depend on how effectively these measures are working to limit cyanobacterial growth and/or to prevent exposure. Assessing a given system's efficacy in controlling this risk requires understanding the entire water-use systems from the catchment or source right through to the point of contact with the end user (e.g., consumers of drinking-water or fish/shellfish, or end users such as those involved in recreation or occupational exposures). Assessing the efficacy of the barriers in place is an essential basis for identifying, planning and implementing priority measures to control the conditions that may cause cyanobacterial blooms, thus limiting human exposure. Further elements essential for planning include time spans expected for control measures to take effect as well as expertise, investments and regulatory frameworks necessary for their implementation.

This chapter presents a proactive risk assessment and management framework that can be applied to identify and manage threats to public health from water-use systems, including cyanotoxins, namely, water safety planning. Water safety planning is advocated for by the World Health Organization (WHO) as the most effective means of ensuring the safety of drinking-water supplies (Rickert et al., 2016). In the context of toxic cyanobacteria, this chapter provides guidance not only on how the Water Safety Plan (WSP) approach can be used to manage the risk of cyanotoxin occurrence in drinking-water, but also on how the framework can be adapted and expanded to consider cyanotoxin exposure from other routes relevant for a given context (e.g., exposure from recreational or occupational contact or food consumption). The approach is illustrated with worked examples from three different scenarios, ranging from larger water-use systems to smaller private supplies.

\section{I LEVELS FOR EXERTING CONTROL OVER CYANOTOXIN OCCURRENCE AND EXPOSURE}

As depicted in Figure 6.1, the most fundamental control level is catchment management to prevent or reduce nutrient loads to the waterbody, particularly those of phosphorus (Chapter 7), and control measures at this level can be supported by measures at the level of waterbody management (Chapter 8). If control measures on these levels are not in place or fail to meet their targets and toxic cyanobacteria proliferate, the remaining management option is to control human exposure. In some situations, this is possible by 
shifting sites for drinking-water offtake or recreation to where cyanobacteria do not accumulate. A further option may be to implement management measures such as mechanical mixing within the waterbody to reduce cyanobacterial biomass (Chapters 8 and 9). For drinking-water, the removal of cyanobacterial cells and/or toxins dissolved in water in the drinking-water treatment plant is an additional important control measure (Chapter 10). For other water uses (e.g., swimming and other recreational contact), the consumption of fish and shellfish or spray irrigation - temporarily limiting or banning use as an emergency response (as discussed in sections 5.2-5.5) may be the only option if cyanotoxin levels are in a range causing exposure to inacceptable concentrations.

A cornerstone of the WSP philosophy is the promotion of a "multiple-barrier approach". This approach advocates for the use of more than one type of barrier or control measure (Figure 6.1) throughout the water-use system (i.e., from the source to the point of use/contact) to minimise risks from cyanotoxin exposure. Through this approach, in the event that an upstream control measure fails (e.g., in the case of a drinking-water supply system, failure of a multilevel raw water offtake), the presence of downstream barriers may still limit the risk from cyanotoxin exposure (e.g., drinking-water treatment optimised to remove cyanotoxins). Exceptions may include settings where risks from cyanotoxin occurrence are considered to be very low, such as pristine and protected catchments that are under the direct control of a single management entity (e.g., water supplier or a catchment management authority).

Targets can be set at each of these levels to achieve the target set for cyanotoxins: a target for cyanobacterial biomass may be based on ratios of toxin to biomass either expected from the literature (section 4.2.6) or determined locally from data for the specific waterbody. A target for limiting the concentration of a key nutrient may be set, for example, in the range of $10-50 \mu \mathrm{g} / \mathrm{L}$ of total phosphorus, depending on the specific characteristics of the waterbody and on how stringently cyanobacterial biomass is to be limited (Chapter 7). The corresponding target for the nutrient load from the catchment to the waterbody depends on further waterbody characteristics, and models are available to determine which load is likely to achieve which concentration in a given waterbody (Chapter 7).

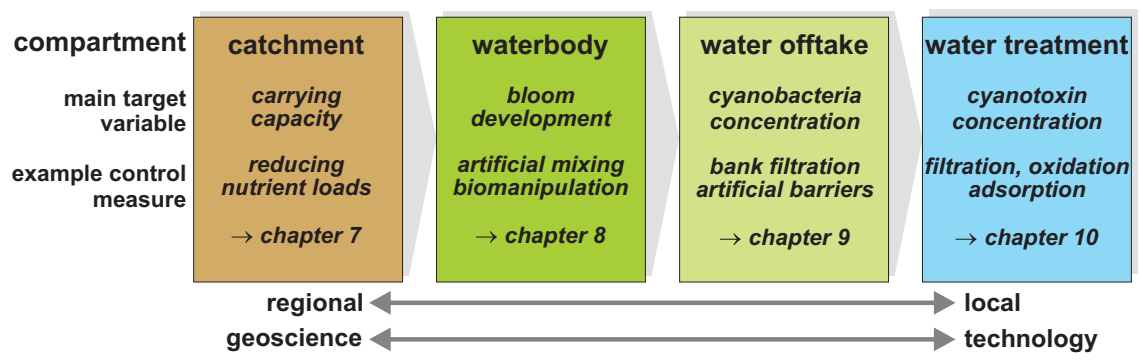

Figure 6.I Levels and scales of measures for controlling cyanotoxin occurrence 
The challenge for management is to set targets based on an assessment of the specific situation to determine which control options are realistically achievable. Depending on the local conditions, this may focus on the activities in the catchment that cause nutrient loads from different effluents and surfaces. Additionally or alternatively, it may involve setting targets for the performance of drinking-water treatment in cyanotoxin removal (Chapter 10), or for public outreach campaigns to inform recreational site users of potential cyanotoxin risks and of prudent behaviour for avoiding exposure (Chapter 15). Thus, decisions on setting targets for a given setting at each of these control levels will depend on the control options available, and setting them effectively requires an understanding of the specific system.

Such an in-depth understanding of the specific setting is most effectively achieved by following the steps of developing a WSP as described in the WHO Guidelines for Drinking-water Quality (WHO, 2017), in the WHO/IWA Water Safety Plan Manual (Bartram et al., 2009; Figure 6.2) or the guidelines for safe recreational environments (WHO, 2003), and extending the approach by considering exposure routes in addition to drinking-water and recreation if these are relevant for the specific system. Further, WHO also provides guidance tailored specifically for water safety planning in small systems (e.g., rural communities; WHO, 2012).

In contexts where a full WSP is not developed, many of the steps and elements of this approach are highly useful for assessing and managing cyanotoxin risks.

\subsection{WATER SAFETY PLANNING AS A FRAMEWORK FOR ASSESSING AND MANAGING CYANOBACTERIAL RISKS}

A comprehensive Water Safety Plan (WSP) should consider the potential risks from all of the threats or "hazards" (i.e., typically microbial, chemical or physical agents that can impact public health or disrupt system operations and service delivery) within the entire water supply system (i.e., at catchment/source, treatment, storage, distribution and consumer levels), as well as the hazardous events that may introduce them. As such, a WSP should not only address cyanobacterial risks, but rather comprehensively assess and prioritise all of the risks from the range of hazards identified for a given supply system. Depending on the local context, cyanotoxins may well not emerge as top priority, depending on the system characteristics and vulnerabilities.

An important outcome of developing a WSP is the prioritisation of measures to be taken to effectively control the most significant risks. Assessing the risks will include the measures that are in place to control them. In the case of cyanobacteria, control measures include natural conditions that may reduce the nutrient loads from the catchment (e.g., riparian vegetation buffer strips) as well as engineered control measures (e.g., mechanical 


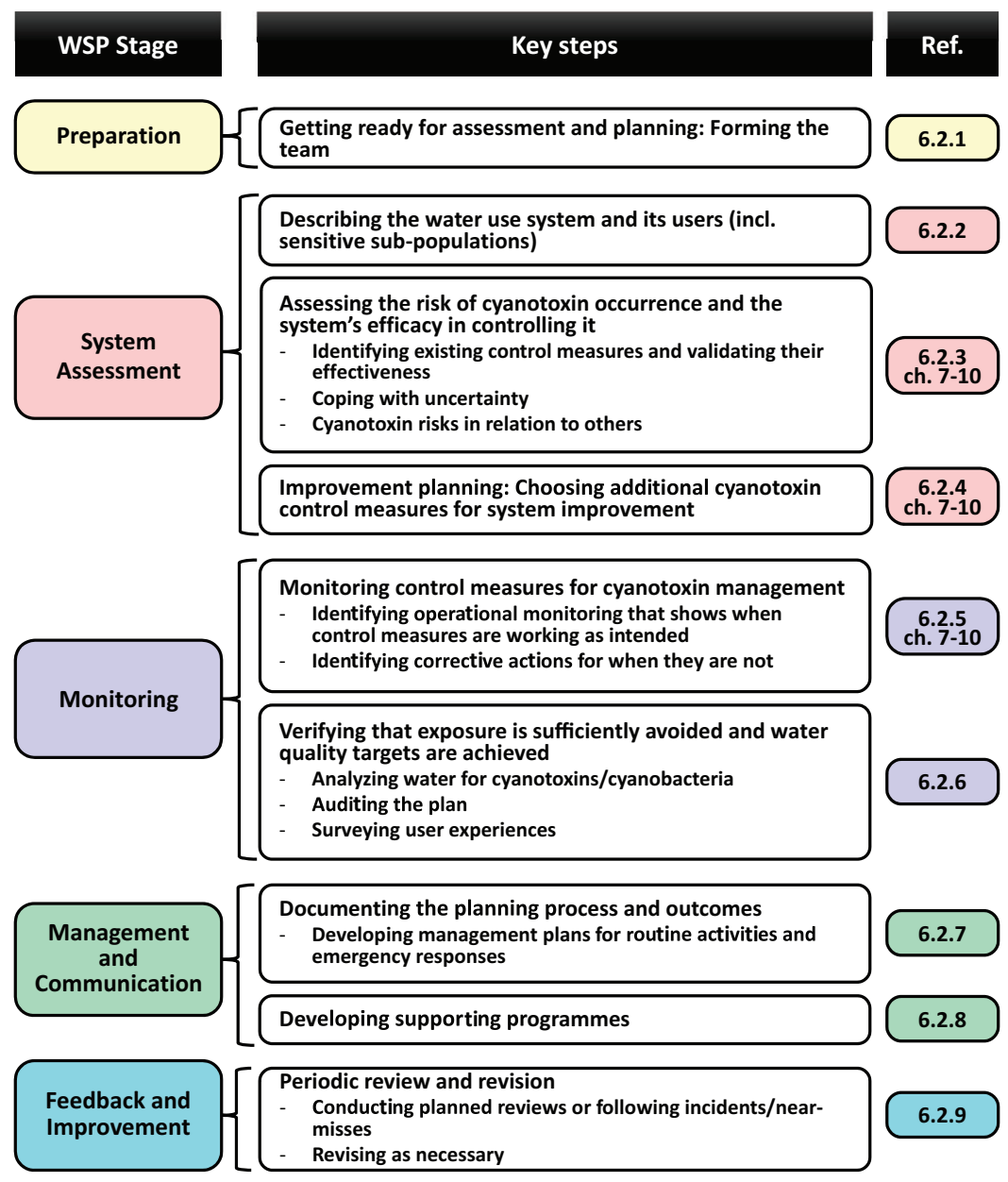

Figure 6.2 Selected steps of developing a Water Safety Plan (WSP) for a specific wateruse system, and corresponding subsections within this chapter. Following these steps is effective for managing cyanotoxin control also when no full WSP is developed.

waterbody mixing) to limit stratification. An important principle of water safety planning is the ongoing routine monitoring of control measures (referred to as "operational monitoring"), which shows that control measures are working within acceptable operational limits, showing that the hazard continues to be managed effectively on an ongoing basis. For control measures to be effective in the longer term (e.g., existing control measures or new, additional control measures implemented in consequence of the risk assessment process), it is prudent to include considerations of how climate change may impact on the given water-use system. 
In addition to upgrading the system to effectively control cyanotoxin hazards, an important element of water safety planning is to include triggers for initiating the short-term management actions (e.g., management of incidents through emergency response plans) to avoid human exposure. A good way to do this is to integrate Alert Levels Frameworks based on the suggestions given in section 5.1 for drinking-water and in section 5.2 for recreational water use. These frameworks outline which exceedances may trigger which responses. An incident response plan, as discussed in Chapter 15 , is a further integral part of a WSP.

Although originally developed to ensure the safety of drinking-water supplies, WSPs are not limited to this application - the WSP framework can equally be adapted and applied for the assessment and management of risks from other potential exposure routes, in particular through recreational water contact. For fish and shellfish, the HACCP (Hazard Analysis Critical Control Points) concept widely required for food production includes very similar steps (as the WSP concept was developed for drinking-water from the widely used HACCP concept for food production) and can readily be linked to the WSP elements which may better address the catchment and waterbody aspects. So can sanitation safety plans (SSPs) - an application of the same concept to systematically identify and manage health risks along the sanitation chain. This approach may also be applied to limit nutrient inputs into water-use systems.

A strong feature of WSP development is documentation, not only of the WSP itself as an outcome of the process, but also of the rationale behind the decisions taken and of the uncertainties as well as the information gaps identified. This chapter therefore illustrates the type of questions to address and considerations to document with worked examples for three situations differing in size, catchment, technology and access to monitoring.

Developing a Water Safety Plan (WSP) is a process typically conducted by a team using the steps described in the following sections. As emphasised above, even where a full WSP is not developed, these steps represent a useful systematic framework for assessing and managing cyanotoxin risks.

\subsection{Getting ready for assessment and planning: forming the team}

The first step is to establish an experienced, multidisciplinary team whose role is to develop and drive the day-to-day implementation of the plan. Assessing and controlling the risk of cyanotoxin occurrence tends to require a broad range of expertise: for example, setting targets in terms of concentrations and loads of phosphorus requires an in-depth understanding of the specific waterbody's hydrological conditions, the land uses and nutrient dynamics. In contrast, setting performance targets in water treatment requires engineering and operational knowledge. Such expertise is spread across different institutions and stakeholders. Moreover, the stakeholders 
to involve for effective cyanotoxin control tend to span quite a range of responsibilities and areas of influence, that is, for activities and hydrological management in the catchment, for managing the waterbody as well as for drinking-water abstraction and treatment. They may also include those using a waterbody for recreation, irrigation or other workplace exposure to spray, as well as fisheries. A drinking-water supplier alone cannot make decisions on measures in the catchment or waterbody (unless the supplier owns the catchment). Rather, the implementation of measures beyond the water supply depends on good cooperation with the other stakeholders. For example, for the catchment aspects of a WSP, an authority responsible for catchment management may already have a leading role in this area. Collaboration in system assessment is also essential in order to gain access to the information needed from the different stakeholders. Furthermore, including stakeholders - particularly for land use in the catchment - early on in the process can develop a sense of ownership and involvement that will facilitate the subsequent implementation of management measures.

This is why developing a WSP typically begins with forming a team of experts. Whether a full WSP is developed or only an approach to controlling cyanotoxin occurrence is sought, such a team is an excellent platform for bringing together stakeholders and information for interdisciplinary and intersectoral collaboration. The team needs the participation of technical operators as well as that of senior managers. The full support of the leading management is essential for allocating staff time and resources. This is particularly relevant when developing a WSP but also applies when the scope of planning is limited to controlling only cyanotoxins. It is also important for later acceptance of control measures and subsequent day-to-day practices, including the implementation and monitoring of system improvements.

Such a team is most effective if it includes people with the competence needed to analyse the factors leading to cyanotoxin risks and the efficacy of the measures in place to control these risks, as well as staff with the authority to implement any further measures decided upon. However, it is useful to limit the core team to those needed throughout the process of developing the WSP, particularly to ensure that all key stakeholders identify themselves with the process and its outcome. In contrast, those needed for the clarification of specific aspects are best included on an ad hoc basis, that is, only when these aspects are discussed. Such specific expertise may include the fields of:

- phytoplankton ecology to understand the likelihood of bloom occurrence;

- nutrient dynamics to set adequate targets for nutrient concentrations and nutrient loading and to propose measures to achieve these targets;

- drinking-water treatment to set performance targets that ensure cyanotoxin removal and - if necessary - to propose further measures to better achieve these targets; 
- analytical skills, ranging from cyanobacterial identification and quantification to cyanotoxin analysis, depending on programmes to be implemented;

- public health and/or water quality who can advise on the health impacts of cyanotoxins and support risk assessment;

- integrated water resource management;

- emergency response planning;

- recreational water management;

- food safety management;

- occupational health and safety management;

- integration of climate change considerations (e.g., climatologist, hydrologist, strategic planners, climate change and public health risk specialist).

Representatives from the relevant end-user groups should also be involved in the process at key stages (e.g., drinking-water users associations, community groups, recreational groups). This can provide important user perspectives from "on the ground", particularly in relation to catchment activities. Such involvement also serves to ensure that the relevant end users are informed and support the process - and thus the longer-term effectiveness and sustainability of its outcomes.

A team leader should be designated who drives the process of Water Safety Plan (WSP) development. If the most important or most sensitive use of a waterbody is the provision of drinking-water, it is usually most effective for the team to be led by the water supplier, while including relevant experts and decision-makers from the catchment and waterbody. However, in certain contexts, and depending on the most sensitive use of water, the WSP may be driven by the authority responsible for public health or for management and protection of surface water. Table 6.1 shows three examples of how teams may vary in size and expertise, depending on the requirements and available options in the respective setting.

It is further useful to define and record the roles and responsibilities of the team members, potentially differentiating between core team members (i.e., those who are responsible for the more day-to-day aspects of WSP implementation) and those who support specific parts of the WSP development. Challenges include finding stakeholders in the catchment who are willing to be involved, potentially with the consequence of changing their way of doing things in order to reduce nutrient loads to the waterbody, holding regular meetings with team members from different organisations over a longer period of time, and finding and involving individuals with sufficient expertise. Chapters 7-10 therefore include guidance on the scientific and technical expertise that may be required. Generic aspects of team formation are discussed - with examples of challenges and benefits in the Water Safety Plan Manual (Bartram et al., 2009) and Water Safety Planning for Small Community Water Supplies (WHO, 2012). 
Table 6.I Three example settings: team composition for assessing and managing the risk of cyanotoxin occurrence

\begin{tabular}{|c|c|}
\hline Examples of settings & Team composition for each of the three settings \\
\hline $\begin{array}{l}\text { I: Slow-flowing large } \\
\text { river serving as raw } \\
\text { water source for } \\
\text { drinking-water for a } \\
\text { town of } 500000 \\
\text { inhabitants }\end{array}$ & $\begin{array}{l}\text { Core team: the water supply's technical manager (team leader); } \\
\text { two operators responsible for abstraction and treatment; an } \\
\text { officer from the local public health authority; a senior officer } \\
\text { from the water board; a representative from the catchment } \\
\text { land-use association. } \\
\text { Expertise consulted on an ad hoc basis: a limnologist, a } \\
\text { hydrogeologist with experience in modelling nutrient loads, a } \\
\text { microbiologist, a climate expert. } \\
\text { Initial management decision: thorough system assessment to } \\
\text { be undertaken; full support to be provided by staff with dedicated } \\
\text { allocation of staff working time for this purpose; regular } \\
\text { presentation of interim results at staff meetings to be undertaken. }\end{array}$ \\
\hline $\begin{array}{l}\text { 2: Reservoir serving } \\
\text { about } 7000 \text { people } \\
\text { (three villages and a } \\
\text { number of farms) }\end{array}$ & $\begin{array}{l}\text { Core team: one engineer (leader), an officer from the local } \\
\text { public health authority, an officer from the environmental } \\
\text { authority and a representative from the local boating club. } \\
\text { No funding is available for external support, but a cooperation } \\
\text { with the hydrobiological faculty of a nearby university will be } \\
\text { undertaken for scientific support; there will be participation in } \\
\text { some relevant scientific and management meetings for } \\
\text { knowledge transfer. }\end{array}$ \\
\hline $\begin{array}{l}\text { 3: Farm dugout } \\
\text { serving as } \\
\text { drinking-water } \\
\text { source for 20-50 } \\
\text { people }\end{array}$ & $\begin{array}{l}\text { The health authority has identified that farm dugouts pose a risk } \\
\text { to human health, both because incidents of diarrhoea are } \\
\text { attributed to Cryptosporidium and because cyanobacterial blooms } \\
\text { are generally frequent in the region. It has therefore invited farm } \\
\text { owners in the region to a series of workshops for assessing the } \\
\text { situation and finding appropriate management solutions, and the } \\
\text { owner of this farm is developing a WSP for her water supply on } \\
\text { the basis of this support. } \\
\text { Core team: the farmer has formed a three-person team for her } \\
\text { farm with herself as the designated team leader, with support } \\
\text { from an officer from the health authority and the farm manager. } \\
\text { An engineer has been contracted for consultation to join } \\
\text { relevant team meetings. }\end{array}$ \\
\hline
\end{tabular}

\subsubsection{Describing the water-use system and its users}

A thorough understanding of the system - from the catchment to user, that is, the point of exposure - is the basis for identifying and assessing hazards/ hazardous events, existing control measures and risks. To facilitate this, an accurate and up-to-date system description should be prepared, which can contribute to system understanding and support the identification of system vulnerabilities and informs the subsequent hazard analysis and risk assessment (Table 6.2). A flow diagram is a helpful tool for visualisation, which can help support the identification of system vulnerabilities in subsequent steps.

A comprehensive description of the water-use system should begin with an inventory of conditions in the catchment that determine water flow, that is, the 
water budget, as well as an estimate of potential pathways for nutrient loading through erosion, seepage, inflows and tributaries. The target is to document geographical and hydrogeological conditions as well as land use that may affect nutrient loads, for example, agriculture, direct discharge of wastewater (including information on wastewater treatment efficacy for removing phosphorus and nitrogen), indirect discharge of wastewater (e.g., seepage/overflow of on-site sanitation systems such as septic tanks or latrines) or manure, drainage from roofs and roads. (For further information and examples of catchment inventories, refer to "Protecting Surface Waters for Health"; Rickert et al., 2016.) The description further includes the morphological, hydrophysical, chemical and biological characteristics of the waterbody. If drinking-water is abstracted, the description covers offtake site(s) and patterns as well as the steps of the treatment train. Where recreational use may lead to cyanotoxin

Table 6.2 Examples of basic system descriptions as a basis for assessing the risk of cyanotoxin occurrence

Example I: Slow-flowing large river serving as raw water source for drinking-water for a town of 500000 inhabitants - summary system description.

$90 \%$ of the (mostly cross-border) catchment is used for agriculture.

Sewage from smaller settlements is discharged up to $50 \mathrm{~km}$ upstream (this is treated, but without nutrient removal [i.e., phosphorous or nitrogen]).

Larger cities are located further upstream.

Heavy cyanobacterial blooms occur every summer with lower biomass persisting in winter; no cyanotoxin data available; climate projections indicate that warmer water temperatures might exacerbate seasonal blooms during the summer.

Drinking-water treatment is in place (system is $>30$ years old) with pre-oxidation, coagulation/ flocculation, filtration and disinfection; powdered activated carbon is stored but rarely used (operators consider the black dust too messy to handle).

Water is distributed via three intermittent storage tanks and piped to households.

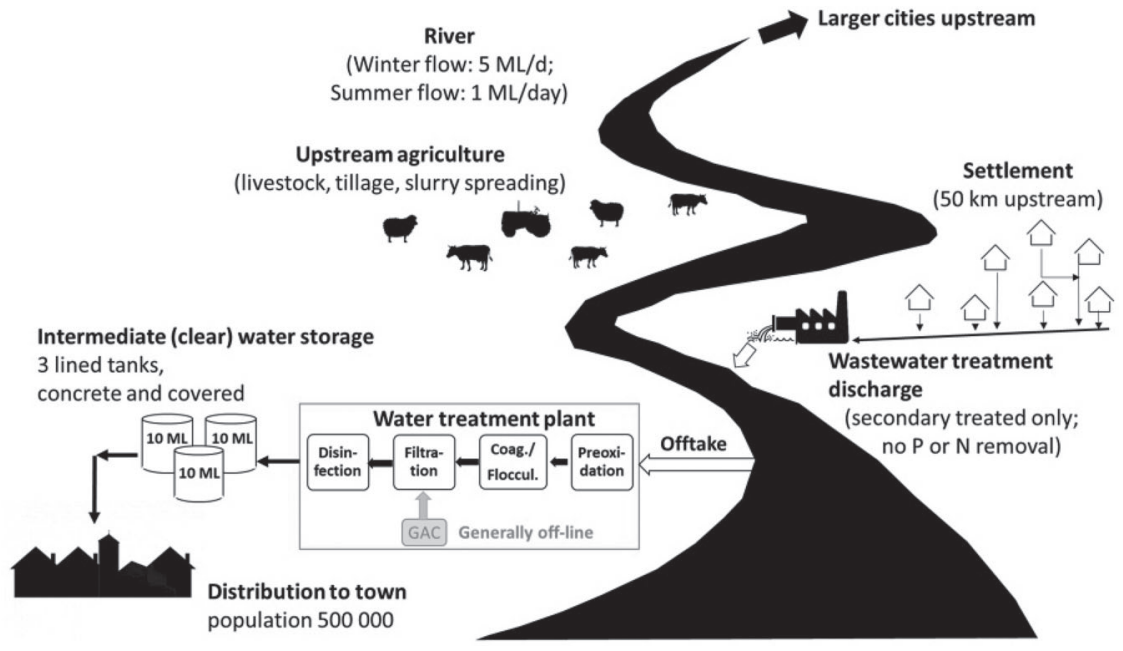


Table 6.2 (Continued) Examples of basic system descriptions as a basis for assessing the risk of cyanotoxin occurrence

Example 2: Reservoir serving about 7000 people, that is, three villages and a number of farms - summary system description

Reservoir is located uphill from the villages and farms in a middle-range mountain area (see diagram for hydrological details); $70 \%$ of the catchment is used for forestry and some hunting; $20 \%$ is rocky and not used; meadow area $(\approx 5 \%)$ is used for extensive sheep farming.

Ecotourism has developed over the past $10-15$ years, including a small hotel ("Ecolodge") with 60 beds, a restaurant, boating club and up to 500 week-end restaurant visitors; the drinking-water supply is from its own spring; wastewater effluent discharges into a septic system (no documentation on the system or effluent volumes discharged is available).

The meadow ends in a small beach with a steep rock which is very popular for diving (no official bathing site, not monitored).

No data on phytoplankton or cyanobacteria, but locals and tourists occasionally report either reddish discoloration (particularly in autumn and winter) or thin bright-green scums in the bay used for swimming.

Drinking-water treatment for the villages and connected farms is limited to flocculation, filtration and disinfection, which may be insufficient during blooms. Piped distribution system is on-premises. Recreational use is banned (to avoid human pathogens in the reservoir) but enforcement is poor.

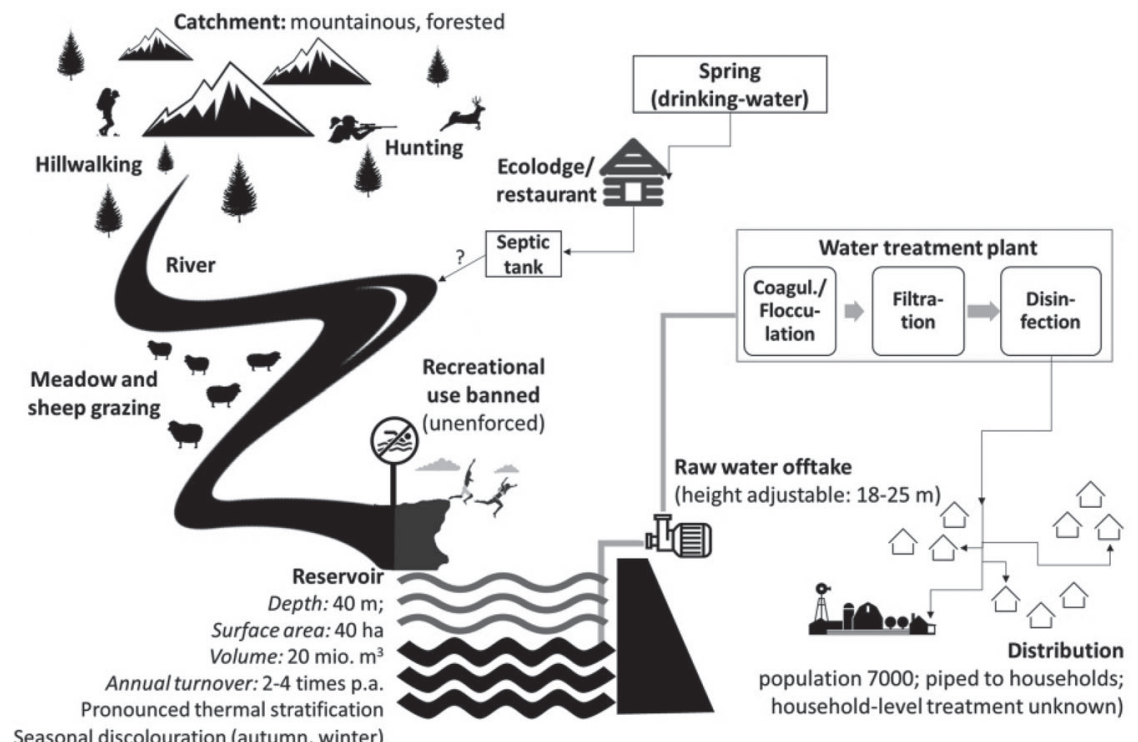

(Continued) 
Table 6.2 (Continued) Examples of basic system descriptions as a basis for assessing the risk of cyanotoxin occurrence

Example 3: Farm dugout serving as water source for 20-50 people - summary of system description

Farm dugout is located at the foot of a hill that is used for cattle grazing; summer cyanobacterial blooms are common.

The extent of groundwater versus surface run-off is unclear but slope and the traces of erosion suggest a fair amount of direct run-off; vegetation cover is only grass and appears ineffective in intercepting run-off carrying phosphorus or nitrogen (or pathogens like Cryptosporidium) from cattle manure; future climate projections indicate more intense rainfall to be expected.

The fence around the dugout is intact and effective in keeping cattle out.

No alternative drinking-water source is available within reasonable distance.

Drilling a deeper well is not an option in this rocky area; funding for expensive interventions is not feasible.

Water for household use is piped directly at $\mathrm{I}-1.5 \mathrm{~m}$ depth; filtration device of unclear design is in place for food preparation.

Site inspection showed a small self-made diving board, with about 15 children in the water (sailboard, swimming, diving, playing in moderate scum).

Impact on local farm produce marketed (e.g., meat, milk and grains) is unlikely; impact on vegetables grown for own use is a possibility, the risk of which is to be included in the assessment.

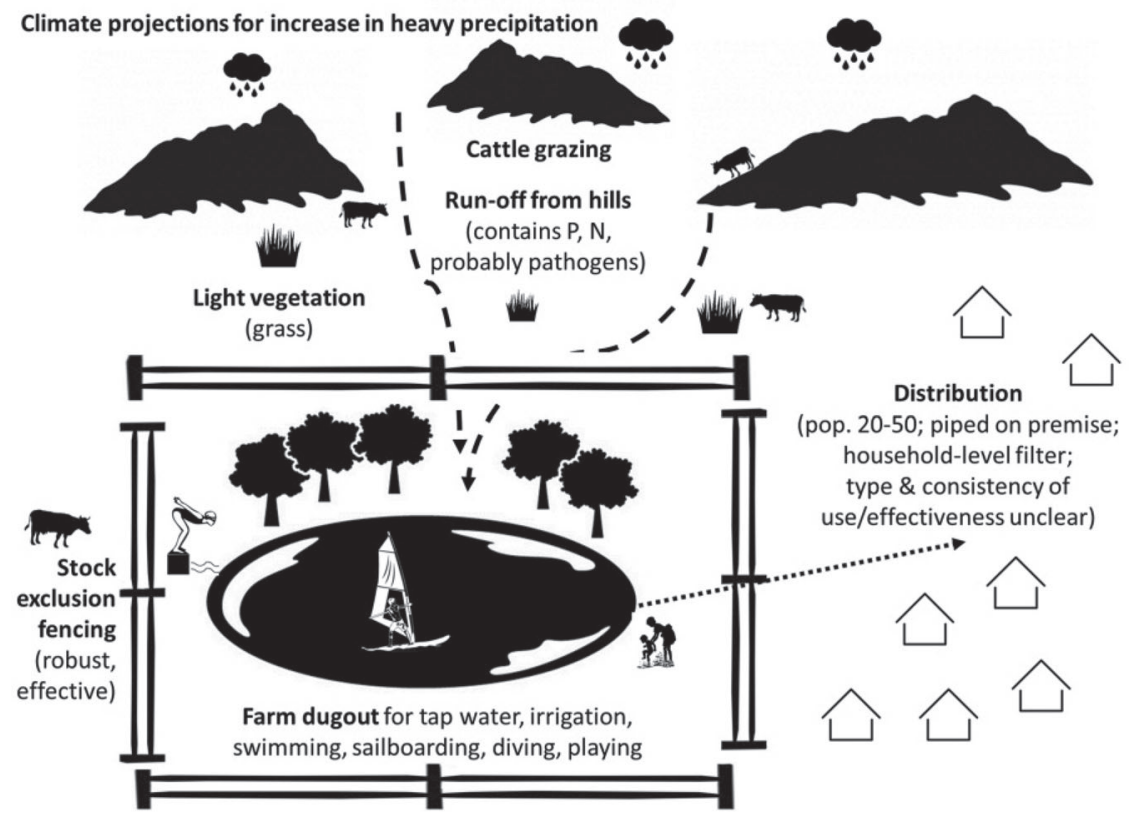

Note: Typically, system flow diagrams would include more detailed information to support subsequent hazard identification and risk assessment, including quantitative or relative relevance information for specific loads and pathways, detailed flow diagrams for water treatment plants. 
exposure, information on bathing sites and other water sport activities relative to prevailing wind directions is important, including time patterns of such activities in order to assess critical periods for exposure. This also applies to other direct water uses potentially causing human exposure, like spray irrigation. Where exposure through food (irrigated vegetables, recreational angling, professional fisheries, aquaculture and mussel harvesting) may be quantitatively relevant, information on the affected crops, fish or mussel species, amounts typically consumed and time patterns of consumption may be important to estimate a potential cyanotoxin dose via food.

Visual inspection of the waterbody and its catchment is a highly valuable basis both for collecting information on the aspects listed above and for validating information gleaned from documents and interviews. This process of "walking the system" can help identify potential threats to the waterbody which cannot be identified through desk-based assessment alone (e.g., activities that are not permitted, but are occurring nevertheless). Such an inspection is best prepared by collating documented information, for example, from authorities managing the waterbody and its tributaries, authorities responsible for issuing permits for discharges into water courses or activities in the catchment, operators of enterprises and activities in the catchment as well as from site users. The latter may include professionals as well as the public, for example, people observing scums and greenish turbidity. Including any available (semi)quantitative information about loads of phosphorus or nitrogen to the waterbody, expected and/or measured concentrations within the waterbody, cyanobacterial biomass or cyanotoxin concentrations is highly useful for the steps of identifying hazards and conducting a risk assessment. Examples of key information to support the description of the water-use system include the following:

- for the catchment: Activities and conditions likely to lead to erosion and nutrient input, particularly during storm events;

- for the waterbody and the catchment: Where available, impacts anticipated in the wake of developments such as land use or climate change, both those currently known and those anticipated for the future;

- for the waterbody: Water quality data as available, in particular nutrient concentrations, Secchi depth readings, phytoplankton data (biomass and extent of cyanobacterial dominance); potentially also data on organisms at higher trophic levels as these may impact on phytoplankton biomass and species composition; any climate change scenario projections available;

- where available, data on cyanobacterial and cyanotoxin occurrence and any indication of human or animal illness suspected to have been caused by these bacteria;

- if the waterbody is used as a drinking-water resource: A description of

- the drinking-water treatment train (e.g., offstream storage reservoirs before or after treatment, pretreatment [e.g., addition of powdered activated carbon, oxidation], coagulation/flocculation, 
sedimentation, dissolved air floatation, filtration, ozonation, granulated activated carbon (GAC) filtration, slow sand or riverbank filtration, disinfection [e.g., chlorination, UV irradiation]);

- the amount of water produced and the households it serves (potentially as map);

- a map of the mains, including reservoirs in the distribution system and their condition, whether these are covered or open (relevant also for other hazards potentially introduced during distribution) and retention time (relevant for cyanotoxin degradation in the mains);

- information on the water users (including any sensitive population groups) and for which purposes it is being used (e.g., drinking, other nondrinking household uses [such as washing, bathing], or sensitive applications [like dialysis]; see below).

Chapters 7-10 give detailed checklists on information to collect and evaluate about the catchment, the waterbody, the location of abstraction points for drinking-water and for bathing sites, and drinking-water treatment. These checklists are intended to support both the description of the system and subsequent risk assessment. Table 6.2 introduces the three examples used in this chapter with a short summary of system descriptions that highlight the potential variability in coverage and amount of information available. Table 6.2 includes basic flow diagrams that provide an illustrative example of how these tools can support the identification of system vulnerabilities.

The typical situation is indeed that not all of the desirable information will be available. The Water Safety Plan (WSP) concept promotes "incremental improvement", that is, encouraging to get started in the first instance, and improve the WSP stepwise over time as capacity and system knowledge build and resources become available. As such, a first iteration of assessing the system and the risk of cyanotoxin occurrence should begin even in the absence of all of the necessary information, to find out which information gaps are the most crucial for the decisions that need to be made. If these gaps prove relevant for the assessment, they will be the first ones to address with targeted programmes. It is important to validate the description of the system through site inspection, particularly from the perspective of identifying any illegal/unauthorised activities in the catchment, and to accurately document the system description.

\subsubsection{Identifying water users and uses (including sensitive subpopulations)}

Assessing who uses the water and for which purposes helps evaluate the public health risk arising from the exposure of the respective population. Information about any groups of the population with specific exposure risks or particularly susceptibility to specific hazards provides a basis for specifically targeted information and warning. In the case of toxic cyanobacterial blooms, such groups might include the following: 
- those preparing dialysis water as well as dialysis users, as dialysis directly exposes people intravenously to large amounts of water (approximately $120 \mathrm{~L}$ per treatment), thus increasing toxicity by at least an order of magnitude (section 5.4). Early information if cyanobacteria build up in the waterbody and cyanotoxins may occur is important, as even trace amounts are of concern for dialysis;

- users of private drinking-water supplies using surface water or shallow wells strongly influenced by a waterbody with blooms (e.g., supplies for holiday houses);

- people potentially exposed via aerosol and small water droplets from the waterbody, for example, through spray irrigation, decorative fountains, or water use for cooling;

- recreational user groups, particularly where exposure is frequently repeated (e.g., sports clubs, lakeside campsites) or where direct contact with bloom material (e.g., water skiing, wind surfing) is likely;

- operators of fisheries and consumers of fish/shellfish.

Using the three examples in this chapter, Table 6.3 highlights how such information may be documented, including existing information gaps to close with high priority.

\subsubsection{Assessing the risk of cyanotoxin occurrence and the system's efficacy in controlling it}

The next step aims to identify:

- Conditions (in particular eutrophication) potentially causing cyanotoxin occurrence.

- Events augmenting this occurrence (e.g., extended spells of warm weather).

- The efficacy of the existing control measures in place (if present) to control the occurrence of cyanobacteria.

- The likelihood of occurrence and severity of the consequences (or impact), resulting in assessment and prioritisation of the risks.

This assessment requires an understanding of potential nutrient sources in the catchment causing eutrophication, conditions causing them to reach the water source, how these pathways are best controlled, whether these existing controls are effective, and if controls at this level fail, how effective downstream control measures are at minimising exposure (e.g., where present, how effectively can downstream drinking-water treatment remove cyanotoxins).

The key steps of risk assessment in the context of Water Safety Plan (WSP) development are summarised briefly here - for detailed information 
Table 6.3 Three example settings: water users/uses documented in the system description for assessing cyanotoxin exposure risk

\begin{tabular}{|c|c|}
\hline Examples of settings & Overview of water uses/users in each of the three settings \\
\hline $\begin{array}{l}\text { I: Slow-flowing large } \\
\text { river serving as raw } \\
\text { water source for } \\
\text { drinking-water for } \\
\text { a town of } 500000 \\
\text { inhabitants }\end{array}$ & $\begin{array}{l}\text { Drinking-water for the population of the town, used also for } \\
\text { standard household activities (washing, bathing, food } \\
\text { preparation, etc.). } \\
\text { - A hospital with a dialysis unit (information gap: find out } \\
\text { whether it buys water specifically designated for dialysis or } \\
\text { uses tap water and conducts its own treatment). } \\
\text { - Water for irrigation pumped from the river, but currently not } \\
\text { for vegetable or fruit crop with direct water contact. } \\
\text { - Private angling - unclear how widespread. }\end{array}$ \\
\hline $\begin{array}{l}\text { 2: Reservoir serving } \\
\text { about } 7000 \text { people } \\
\text { (three villages and } \\
\text { a number of farms) }\end{array}$ & $\begin{array}{l}\text { Drinking-water for the villages and farms, used also for } \\
\text { standard household activities. } \\
\text { Some recreational uses at the beach at the bay near the } \\
\text { ecolodge, boating. }\end{array}$ \\
\hline $\begin{array}{l}\text { 3: Farm dugout } \\
\text { serving as water } \\
\text { source for } 20-50 \\
\text { people }\end{array}$ & $\begin{array}{l}\text { - For standard household activities, including food preparation } \\
\text { for the } 20 \text { persons living on the farm and for up to } 30 \\
\text { workers commuting daily; inhabitants and workers emphasise } \\
\text { that they drink bottled water. } \\
\text { - Intensively for swimming by the children of the family, the } \\
\text { farm workers and their friends (information gap: clarify } \\
\text { awareness of the need to avoid ingesting water or inhaling } \\
\text { aerosol and spay). } \\
\text { - Irrigation of the farm's vegetable garden for own use; } \\
\text { no produce sold. }\end{array}$ \\
\hline
\end{tabular}

on the theory and practical application of risk assessment through the WSP process, refer to the Water Safety Plan Manual (Bartram et al., 2009) or Water Safety Planning for Small Community Water Supplies (WHO, 2012).

For assessing the risk of cyanotoxins to occur, it is important to firstly identify hazardous events from the source through to the point of contact with the end user that may result in cyanotoxin occurrence and exposure. Such hazardous events may range from stormwater run-off and tributaries introducing nutrients resulting in bloom occurrence to failure of a water treatment plant component to remove toxins.

To assess the likelihood of cyanotoxin occurrence, any observations on the patterns of cyanobacterial occurrence in the waterbody are valuable, and people living near the waterbody or regularly visiting it may provide important information. Checklist 8.1 in Chapter 8 shows the type of questions to ask regarding direct indication of the occurrence of potentially toxic cyanobacteria. However, blooms can be short-lived periodic events and may well be missed unless observations are quite frequent (e.g., twice a month or even weekly during seasons in which blooms are most likely). Therefore, and to address the potential causes of blooms, it is important to understand which activities in the catchment (in particular intensive farming and wastewater 
inflow) might lead to nutrient loads causing eutrophication and whether conditions within the waterbody are conducive to bloom formation. To support this assessment, Chapter 7 discusses key causes of nutrient loads to the waterbody and provides checklists for assessing conditions and activities in the catchment that are likely to contribute them, and Chapter 8 discusses the conditions within it that determine phytoplankton biomass and species dominance.

The severity of the impact of cyanotoxin occurrence may be determined from the toxin concentrations in relation to the guideline values discussed in Chapter 2 and summarised in Table 5.1, from the size of the population affected, and the duration of the exposure (as depicted for recreational exposure in Table 5.4 in section 5.2).

When determining the likelihood and severity of the consequences of a particular hazard or hazardous event, it is important that the risk assessment include the identification and assessment (or "validation") of the existing control measures that are already in place within the water-use system to determine

- whether the control measures in place are fundamentally capable of effectively controlling the hazard/hazardous event;

- any information gaps and uncertainties of this assessment.

Risk assessment matrices relating the likelihood of hazards/hazardous events to occur against the severity of their impact are frequently used to help understand and make transparent the underlying assumptions leading the assessment. Note that such an assessment can not only be made for a drinking-water system, as is typically done when developing a Water Safety Plan (WSP), but can also be adapted for the whole of the relevant exposure pathways to water containing cyanobacteria, as is the case in the three examples in Tables 6.1-6.7. While such assessments are inevitably somewhat subjective and their value does not lie in finding "absolute truth", they prove valuable for stepwise, systematic and consistent identification, assessment and prioritisation of risks, particularly if the team agrees on definitions for likelihood and severity prior to the assessment. Their value particularly lies in making transparent the (otherwise merely implicit) assumptions that drive decisions on implementing control measures. This transparency makes the assumptions accessible to debate and the decisions accessible to potential improvement.

If the risk assessment identifies that the risk is not adequately managed (e.g., there are no control measures in place, or the existing control measures in place are insufficient to effectively manage the risk), the next step is to suggest upgrading the control measures or to propose new ones for implementation (typically documented in an "improvement plan"; see section 6.2.4).

If the outcome of the risk assessment is that the risk is adequately controlled, typically no further improvement actions (or additional control measures) are required. This would be a very important outcome of the risk 
assessment: if it shows, for example, that nutrient loads to the waterbody are low and not likely to lead to concentrations supporting a substantial biomass of cyanobacteria or that conditions within the waterbody are not conducive to cyanobacterial blooms, it is worthwhile to understand which conditions and control measures are currently maintaining the good situation. An important outcome of the assessment then is that these beneficial conditions should be maintained. For example, if the assessment shows land in the catchment to be chiefly covered by pristine vegetation and in parts used for forestry, a decision may be to maintain this for sustainable future use of the water resource rather than to re-designate it for farming or urban development. It is also important to ensure proper documentation of the assessment as basis for any future planning of land use and permits for new activities in the catchment.

For the three case examples used in this chapter, Table 6.4 shows how the respective teams assessed the health risks due to cyanotoxin occurrence.

Table 6.4 Three example settings: outcomes from assessments of the risk of cyanotoxins to occur in health-relevant concentrations and the reasoning leading to the assessments

Example I: Slow-flowing large river serving as raw water source for drinking-water for a town of 500000 inhabitants

\begin{tabular}{|c|c|c|c|c|}
\hline & \multicolumn{3}{|c|}{ Severity of public health impact } \\
\hline & & Minor impact & Moderate impact & Major impact \\
\hline \multirow{3}{*}{ 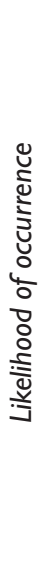 } & Often & & $\begin{array}{l}\text { Exposure to } \\
\text { cyanotoxins in } \\
\text { drinking-water (chiefly } \\
\text { microcystins) due to } \\
\text { ineffective water } \\
\text { treatment }\end{array}$ & \\
\hline & Occasional & & & \\
\hline & Rarely & $\begin{array}{l}\text { Exposure to } \\
\text { cyanotoxins due to } \\
\text { recreational contact } \\
\text { (bathing) } \\
\text { Exposure to } \\
\text { cyanotoxins due to } \\
\text { the consumption of } \\
\text { contaminated foods }\end{array}$ & & \\
\hline
\end{tabular}

Dark grey=high risk; Medium grey= medium risk; Light grey=low risk

\section{Rationale:}

Blooms, particularly of Microcystis and Planktothrix agardhii, documented by the water board and the drinking-water supplier, last up to 3 months during summer; they were extreme during unusually extended periods of drought $I$ and 3 years ago.

Phosphorus concentrations of 60 to $>250 \mu \mathrm{g} / \mathrm{L}$ sustain blooms; very slow river flow promotes their persistence; sources are primarily from two other upstream countries 
and reduction only possible through agreements established in the international river basin commission, possible only in the longer term.

Shifting the site for the drinking-water offtake is not an option, as cyanobacterial biomass is evenly distributed across the river profile.

Drinking-water treatment will currently remove only cell-bound cyanotoxins and reliability of operations for this is not certain.

Resulting exposure risks are as follows:

- high for drinking-water, as current treatment system is inadequate for the removal of dissolved cyanotoxins;

- low for recreation; this use is banned because of heavy ship traffic;

- low for food - no professional fishery, almost no private angling; crops directly irrigated from the river are limited to grain and fruit trees (none that are eaten directly such as lettuce or strawberries).

Example 2: Reservoir serving about 7000 people - three villages and a number of farms

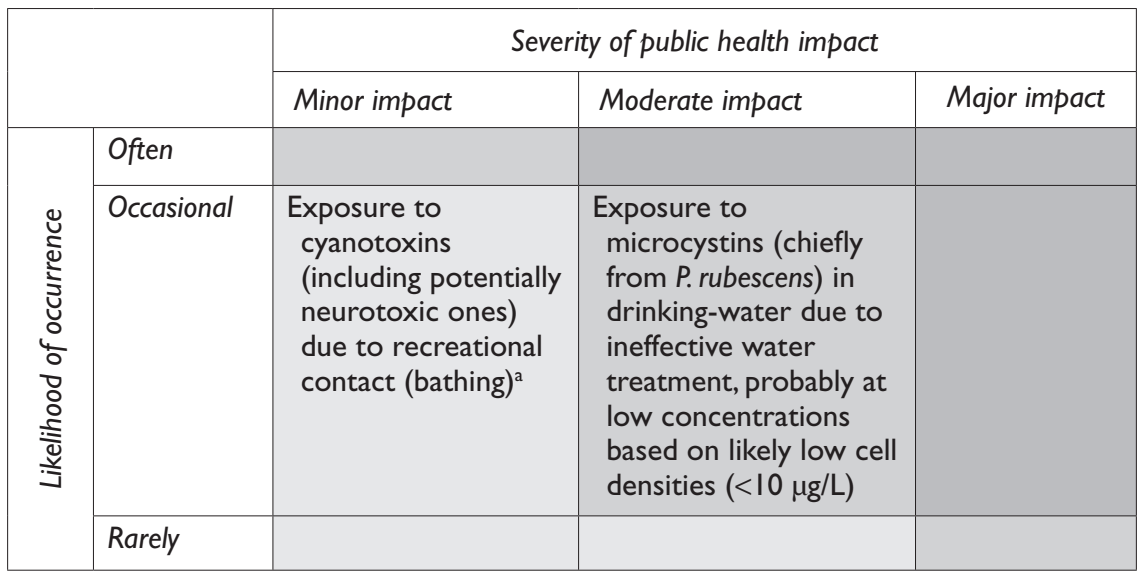

Dark grey=high risk; Medium grey=medium risk; Light grey=low risk

\section{Rationale:}

High levels of turbidity at the thermocline but rarely in raw water; visual reports of sometimes wine-red and sometimes bright-green thin surface films covering a small part of the shoreline water; this indicates Planktothrix rubescens (red) and Dolichospermum sp. (green) likely at low cell density.

Assessment is uncertain; improvement would be through data on phytoplankton species, toxins and nutrient concentrations, but nutrients are likely low because of the catchment conditions.

Resulting exposure risks are as follows:

- drinking-water risk from microcystins most likely low, but classified as medium as default assumption until data available;

- low for recreational exposure: even if the occasional scums consist of neurotoxic Dolichospermum, scum is too limited to cause substantial exposure;

- not given for food as no exposure pathways were identified.

Population potentially affected is small; financial resources are very limited; data gaps to be reduced where cooperation with the university allows, but not as high priority of the public surveillance authority. 
Example 3: Farm dugout serving as water source for $20-50$ people

\begin{tabular}{|c|c|c|c|c|}
\hline & \multicolumn{3}{|c|}{ Severity of public health impact } \\
\hline & & Minor impact & Moderate impact & Major impact \\
\hline \multirow{3}{*}{ 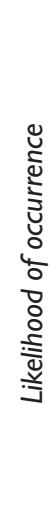 } & Often & & & \\
\hline & Occasional & $\begin{array}{l}\text { Exposure to } \\
\text { cyanotoxins due to } \\
\text { the consumption of } \\
\text { contaminated foods } \\
\text { (i.e., cyanotoxins on } \\
\text { irrigated vegetables } \\
\text { and fruit)a }\end{array}$ & $\begin{array}{l}\text { Possible exposure to } \\
\text { cyanotoxins in } \\
\text { drinking-water due to } \\
\text { uncertain reliability of } \\
\text { household-level } \\
\text { treatment } \\
\text { Exposure (including } \\
\text { young children) to } \\
\text { cyanotoxins due to }^{\text {recreational contact }} \\
\text { (bathing) }^{\text {a }}\end{array}$ & \\
\hline & Rarely & & & \\
\hline
\end{tabular}

Dark grey=high risk; Medium grey= medium risk; Light grey=low risk

\section{Rationale:}

Local residents describe observations on bloom intensity (including some photographs) and duration typically lasting for about one week, sometimes more.

Results of three summer sampling campaigns: total phosphorus $40-55 \mu \mathrm{g} / \mathrm{L}$, high turbidity (possibly due in part to suspended clay particles), and Microcystis biovolume up to $10 \mathrm{~mm}^{3} / \mathrm{L}$, slight scum, microcystins $0.3-1.7 \mu \mathrm{g} / \mathrm{L}$ (determined by ELISA).

Phosphorus loads are uncertain; site inspection suggests primary source is run-off from pasture (mostly cattle) around the dugout.

Awareness of residents and workers is well developed: all individuals addressed during site inspection emphasised bad taste from the dugout water and drinking only bottled water (although the reliability of this appears uncertain for children).

Tap water appears to be filtered for preparing tea and coffee (a filter is installed under the kitchen sink); efficacy of the filter is unclear; it is also unclear to which extent this is used for preparing food.

Exposure of children due to recreational activities is evident.

Resulting exposure risks are as follows:

- likely low for drinking-water but provisionally documented as medium given that the uncertainty of the assessment is substantial;

- moderate for recreational use: exposure of children, including small ones, is repeated at almost daily intervals for many successive weeks on end, but often without the presence of blooms;

- low for food, while not totally to be excluded if lettuce and strawberries (grown for own use) are irrigated with scum (thorough washing should be recommended).

Note: The above tables include a number of risks (denoted by ${ }^{\mathrm{a}}$ ) that are not typically considered under a conventional WSP for drinking-water, but would be assessed in a risk assessment/management plan for recreational water safety, or for food under the similar principles of HACCP.

\subsubsection{Coping with uncertainty}

Collating in-depth information for risk assessment can be an extensively time-consuming exercise, and often information will not be readily available. Estimating nutrient loads from the catchment, understanding the ecological 
interactions within the waterbody and collecting information on socioeconomic aspects of water-use patterns may be particularly challenging. Therefore, it is necessary to consider the detail of information required for making decisions - possibly only preliminary ones, documenting uncertainties and information gaps along with the information. Risk assessment will then show which information gaps and uncertainties most urgently need to be closed, that is, those for which uncertainty precludes decision-making.

For example, reducing uncertainties in estimating a nutrient load may be critically important in a setting where controlling nutrient loading is the key measure to avoid cyanobacterial proliferation and thus cyanotoxin occurrence (e.g., an upstream reservoir in a fairly pristine catchment). In contrast, in a setting where nutrient loads and concentrations in the waterbody are already excessively high and not readily amenable to local control (e.g., a downstream river reach with complex transnational nutrient sources), identifying key nutrient sources and taking action to reduce loads remain important in face of long-term benefits, but in the shorter term, other control measures may need to take priority.

Therefore, risk assessment is an iterative rather than a linear process: it should incorporate the WSP principle of "incremental improvement" as described above, with an emphasis on the importance of getting started and improving over time as information becomes available.

For the three case examples used in this chapter, Table 6.5 shows how the respective teams described the uncertainties of their risk assessments.

Documenting uncertainties and making them transparent, including information gaps to close, are important. This will inform decisions on which measures to take first - whether these should be interventions to reduce exposure or rather programmes to collect data and information before decisions on any investments into measures are to be made.

\subsubsection{Cyanotoxin risks in relation to other public health risks from exposure to water}

A key purpose of risk assessment in water safety planning is to determine priorities for maintaining, upgrading or implementing measures to control public health impacts from the hazards identified. For the overall target of protecting public health, it is important to assess the public health risk from cyanotoxins in relation to that from other hazards/hazardous events potentially occurring in the water. This is also useful because some of the events causing other hazards will also cause cyanobacteria - for example, sewage loads carry both nutrients that support blooms and pathogens. A comprehensive risk assessment would be developed in the context of developing a full WSP, but it is also valuable to contextualise the potential cyanotoxin risk even without developing a complete WSP. Generally, public health risks from pathogens in the water are likely to be of higher priority 
Table 6.5 Three example settings: uncertainties arising during the assessments of the risk of cyanotoxins to occur in health-relevant concentrations

Examples of settings

I: Slow-flowing large river serving as raw water source for drinking-water for a town of 500000 inhabitants

2: Reservoir serving about 7000 people (three villages and a number of farms)

3: Farm dugout serving as water source for $20-50$ people
Uncertainties of the risk assessment for each of the three settings introduced in Table 6.I

Uncertainty due to the lack of cyanotoxin data, but the dominant cyanobacterial taxa almost certainly contain microcystins, and steps available in the drinking-water treatment system - while probably removing cells containing toxin - cannot remove dissolved toxins and may well lead to the lysis of some cells, thus releasing further toxins. Therefore, even without toxin data, exposure to microcystin concentrations in the range of a few $\mu \mathrm{g} / \mathrm{L}$ is likely, particularly as occurrence is ongoing for periods of several months on end.

While uncertainty regarding the extent of private angling is high, it is clear that this lead to relevant exposure only for a small population, possibly for some people with low income frequently relying on fish from the river as a relevant source of protein.

Uncertainty is considerable: although the visual reports suggest cyanobacteria to be the cause, it is unclear whether they indeed cause the discoloration. While catchment conditions do not indicate sufficiently high nutrient loads to support substantial biomass, this cannot be totally excluded, particularly in face of increasing tourism.

Uncertainty regarding concentrations of phosphorus as well as cyanobacterial taxa and their concentrations is relevant, as the data from the three sampling occasions suggest them to be only slightly above thresholds for interventions to prevent human exposure, thus indicating that interventions to reduce phosphorus loads from erosion may be effective.

As finances for a more intensive monitoring programme are lacking, uncertainty will be addressed by intensified visual inspection for blooms.

Uncertainty also exists with regard to the efficacy of the point of use filters and whether filtered water is reliably used for food preparation or not.

due to the potential for severe acute illness, even death, and also because even a small number of people infected through exposure to water containing pathogens can communicate the infection to a potentially exponentially increasing number of others.

For the three case examples used in this chapter, Table 6.6 shows how the respective teams related the health risks due to cyanotoxins to other health risks in the respective setting. 
Table 6.6 Three example settings: health risk assessments due to cyanotoxins in relation to risks from other hazards

Example I: Slow-flowing large river serving as raw water source for a town of 500000 inhabitants

\begin{tabular}{|c|c|c|c|c|}
\hline & \multicolumn{3}{|c|}{ Severity of public health impact } \\
\hline & & Minor impact & Moderate impact & Major impact \\
\hline \multirow{3}{*}{ 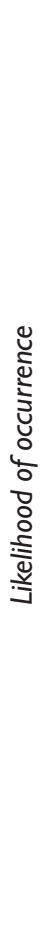 } & Often & $\begin{array}{l}\text { Contamination of } \\
\text { drinking-water with } \\
\text { musty taste and } \\
\text { odour (of unclear } \\
\text { origin) possibly due } \\
\text { to ineffective water } \\
\text { treatment }\end{array}$ & $\begin{array}{l}\text { Exposure to } \\
\text { cyanotoxins in } \\
\text { drinking-water } \\
\text { (chiefly microcystins) } \\
\text { due to insufficiently } \\
\text { effective water } \\
\text { treatment }\end{array}$ & $\begin{array}{l}\text { Microbial } \\
\text { contamination } \\
\text { of the drinking- } \\
\text { water due to } \\
\text { failure of } \\
\text { filtration in } \\
\text { water treatment }\end{array}$ \\
\hline & Occasional & & & $\begin{array}{l}\text { Microbial } \\
\text { contamination } \\
\text { (i.e., Legionella) } \\
\text { in household } \\
\text { installations due } \\
\text { to inappropriate } \\
\text { management of } \\
\text { internal } \\
\text { plumbing } \\
\text { systems }\end{array}$ \\
\hline & Rarely & $\begin{array}{l}\text { Exposure to } \\
\text { cyanotoxins due to } \\
\text { recreational contact } \\
\text { (bathing) }^{\mathrm{a}} \\
\text { Exposure to } \\
\text { cyanotoxins due to } \\
\text { the consumption of } \\
\text { contaminated foods }^{\mathrm{a}}\end{array}$ & $\begin{array}{l}\text { Chemical } \\
\text { contamination of } \\
\text { source water due to } \\
\text { spills of hazardous } \\
\text { chemicals }\end{array}$ & $\begin{array}{l}\text { Drowning, } \\
\text { injuries due to } \\
\text { illegal swimming } \\
\text { in boating } \\
\text { channels } *\end{array}$ \\
\hline
\end{tabular}

Dark grey=high risk; Medium grey= medium risk; Light grey $=$ low risk

Rationale: high risk from cyanotoxins (see Table 6.4); high risk of pathogen breakthrough, particularly of Cryptosporidium (which are resistant to disinfection). Legionella are known to have caused numerous cases of serious pneumonia and two deaths in two hotels and one senior citizens' residence. Public concern is high for spills of hazardous chemicals but actual risks are low, due to the lack of industry in nearer catchment (if they occur, concentrations would be low). Slight risk from musty taste and odour with increased risk if people use other less safe water sources. Two known incidents of teenagers severely injured by boats when swimming in spite of warning notices. 
Example 2: Reservoir serving about 7000 people - three villages and a number of farms

\begin{tabular}{|c|c|c|c|c|}
\hline & \multicolumn{3}{|c|}{ Severity of public health impact } \\
\hline & & Minor impact & Moderate impact & Major impact \\
\hline \multirow{3}{*}{ 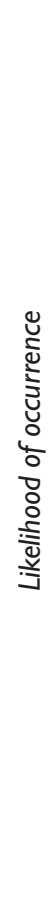 } & Often & 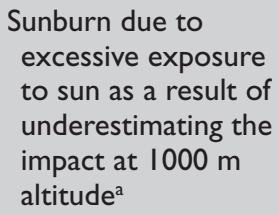 & & \\
\hline & Occasional & $\begin{array}{l}\text { Exposure to } \\
\text { cyanotoxins } \\
\text { (including } \\
\text { potentially } \\
\text { neurotoxic ones) } \\
\text { due to recreational }_{\text {contact (bathing) }}\end{array}$ & $\begin{array}{l}\text { Exposure to } \\
\text { microcystins (chiefly } \\
\text { from P. rubescens) in } \\
\text { drinking-water due to } \\
\text { ineffective water } \\
\text { treatment, probably } \\
\text { at low concentrations } \\
\text { based on likely low } \\
\text { cell densities ( }<10 \\
\mu \mathrm{g} / \mathrm{L})\end{array}$ & $\begin{array}{l}\text { Cranial and spinal } \\
\text { injury due to } \\
\text { unsafe diving }\end{array}$ \\
\hline & Rarely & & $\begin{array}{l}\text { Microbial } \\
\text { contamination of } \\
\text { drinking-water due } \\
\text { to the presence of } \\
\text { inadequately } \\
\text { treated human } \\
\text { effluent from the } \\
\text { bathing area }\end{array}$ & \\
\hline
\end{tabular}

Dark grey=high risk; Medium grey= medium risk; Light grey=low risk

Rationale: risks from cyanotoxins provisionally moderate for drinking-water and low for recreation (see Table 6.4). Diving injuries reported more than once a year; sunburn frequently. Pathogens from sewage seeping through rock fissures and from people using the beach are not likely to reach the waterworks (inactivation by long travel times in the reservoir). 
Example 3: Farm dugout serving as water source for $20-50$ people

\begin{tabular}{|c|c|c|c|c|}
\hline & \multicolumn{3}{|c|}{ Severity of public health impact } \\
\hline & & Minor impact & Moderate impact & Major impact \\
\hline \multirow{3}{*}{ 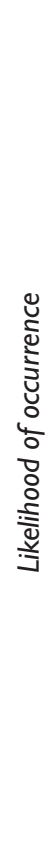 } & Often & & & $\begin{array}{l}\text { Microbial } \\
\text { contamination } \\
\text { of farm } \\
\text { reservoir used } \\
\text { for } \\
\text { drinking-water } \\
\text { due to } \\
\text { defecation and } \\
\text { run-off from } \\
\text { livestock }\end{array}$ \\
\hline & Occasional & $\begin{array}{l}\text { Exposure to } \\
\text { cyanotoxins due to } \\
\text { the consumption of } \\
\text { contaminated foods } \\
\text { (i.e., cyanotoxins on } \\
\text { irrigated vegetables } \\
\text { and fruit) }\end{array}$ & $\begin{array}{l}\text { Possible exposure to } \\
\text { cyanotoxins in } \\
\text { drinking-water due } \\
\text { to uncertain } \\
\text { reliability of } \\
\text { household-level } \\
\text { treatment } \\
\text { Exposure (including } \\
\text { young children) to } \\
\text { cyanotoxins due to } \\
\text { recreational contact } \\
\text { (bathing) }^{\text {a }}\end{array}$ & \\
\hline & Rarely & & & \\
\hline
\end{tabular}

Dark grey=high risk; Medium grey=medium risk; Light grey=low risk

Rationale: moderate risks exists from exposure to cyanotoxins through recreational contact, low for foods (see Table 6.4). Cryptosporidium likely, due to cattle uphill of the dugout, which may cause severe illness, so risk is high.

Note: The above tables include a number of risks (denoted by a) that are not typically considered under a conventional WSP for drinking-water, but would be assessed in a risk assessment/ management plan for recreational water safety or for food under the similar principles of HACCP.

\subsubsection{Improvement planning: choosing additional cyanotoxin control measures for system improvement}

If the outcome of the risk assessment identifies that high-priority risks are not adequately managed, then upgrade of exiting controls and/or additional control measures are needed. These actions are typically documented in an "improvement plan", which should capture which improvement is needed, 
who is responsible for doing it, by when should it be done (i.e., reflecting its priority) and how the improvement will be funded.

Measures to control the risk of human exposure to cyanobacterial blooms range from simple physical interventions like vegetation buffer strips around a waterbody, or behavioural ones like banning recreational use of a waterbody, to more complex technical interventions like the implementation and use of appropriate drinking-water treatment trains. Examples of additional control measures to consider at the different stages of the water-use system are provided in Chapters $7-10$, and for the three scenarios, they are presented in Table 6.7.

\subsubsection{Monitoring the functioning of control measures for cyanotoxin management and developing a management plan}

Validation determines that a control measure is fundamentally capable of controlling a hazard/hazardous event (see section 6.2.3). However, to determine that the control measure actually does continue to function effectively over time, routine monitoring is required (referred to as "operational monitoring"). This will show whether the control measure is reliably managed/ operated such that it continues to provide effective protection. Ideally, operational monitoring should use quick and simple monitoring parameters (see below) that provide a rapid result so the performance of a control measure can be continuously determined, and if necessary, corrective action can be taken in an efficient and timely manner.

Operational monitoring also requires setting performance criteria for the respective control measure and critical limits which indicate if the measure is working within the established acceptable performance criteria. Furthermore, it is useful to define corrective action(s) to be taken if the monitoring shows that the control measure is no longer working within the critical limits. For example, for filtration to remove cyanobacterial cells in drinking-water treatment, turbidity, measured continuously at the outflow of each individual filter, is a simple operational monitoring parameter that indicates whether filtration is working optimally. Critical turbidity limits can be set, and if they are exceeded, this would indicate that the filtration processes are not operating optimally, triggering, for example, filter backwashing as the corrective action to restore optimal operation of the control measure.

This approach can be similarly applied to control measures in catchment or offtake management; for example, vegetation cover to prevent erosion from catchment areas identified as critical for the nutrient load to the waterbody can be defined as control measure, compliance to which can be monitored either by remote sensing or by periodic site inspection. If such monitoring detects violation, corrective action would be an immediate enforcement of revegetation and compliance to the dedicated land use. Likewise, adjusting the drinking-water offtake depth to avoid cyanobacterial intake can be defined as a control measure with online monitoring of 
Table 6.7 Three example settings: additional measures to control cyanotoxin risks and their operational monitoring identified through WSP development

Examples of settings

I: Slow-flowing large river serving as raw water source for a town of 500000 inhabitants

2: Reservoir serving about 7000 people (three villages and a number of farms)

3: Farm dugout serving as water source for $20-50$ people
Additional control measures and their operational monitoring identified for each of the three settings

Implement Alert Levels Framework; install an online fluorescence analyser to indicate when cyanobacterial levels are $>\mid \mu \mathrm{g} / \mathrm{L}$ at raw water intake to trigger microscopy for cyanobacteria; incident response plans to be developed as part of an emergency response.

Upgrade the drinking-water filtration system in the treatment train (see technical specification for details) to ensure an effective cell removal avoiding rupture and lysis (note: this will also reduce risks of breakthrough of disinfection-resistant pathogens). For operational monitoring: install online turbidity analyser (with corresponding "auto dial" alarming for operator notification) at the outlet of each filter.

Any investment into treatment targeting cyanotoxin removal may well prove futile; as a first step, gain the necessary data via the university collaboration described in Table 6. I; decide on appropriate control measures only after the data are available.

Plant a vegetation buffer strip of $10 \mathrm{~m}$ between the uphill pasture and the dugout (this likely represents a sufficient intervention to reduce loads from erosion; note: this will also intercept particles like pathogens, reducing infection risks).

Encourage farm inhabitants and farm workers to continue to drink bottled water, to ensure children understand this, and to use packaged water for food preparation.

Replace the filtration device in the kitchen by one with a carbon cartridge with regular renewal following the manufacturer's instructions.

Ensure children understand the need to avoid swallowing water when using the dugout for recreation and to keep out of scum.

Advise to water the vegetable garden via the soil rather than causing direct water contact with produce.

Operational monitoring of the vegetation buffer strip through visual inspection - annually by the public authority responsible for oversight, by the farmer herself at monthly intervals as well as during and after stormwater events to look for traces of erosion and for immediate repair of any damage.

Operational monitoring of behaviour by spontaneous random household surveys of people on the premises during inspections to check their awareness. 
a characteristic cyanobacterial pigment, phycocyanin, with a specific fluorescence probe as a means of operational monitoring. Critical fluorescence limits can be set, and if they are exceeded, this would inform managers that they need to take corrective action by switching the offtake to a different depth or site, or temporarily ceasing raw water harvesting.

Operational monitoring aims to ensure that the water-use system is "proactively" managed to avoid human exposure to unsafe water (e.g., containing cyanotoxin concentrations exceeding the guideline values or prevailing national standards). Proactive management can thus be far more effective (and less costly) than reacting to water quality issues after they have arisen. Additionally, operational monitoring is more practical and cost-effective than relying primarily on cyanotoxin monitoring. Evidently, by the time violation of a land-use plan has led to cyanobacterial blooms that show up in cyanotoxin monitoring data, "fixing the problem" has become far more difficult. Similarly, by the time cyanotoxin monitoring data show that the water quality target for finished drinking-water is exceeded, the water has already reached the consumer, whereas routine process monitoring would indicate the development of the problem (e.g., declining filter performance) with time to fix it before it leads to high levels of toxin concentrations. Chapters 7-10 therefore include text and tables suggesting the selected examples of control measures that can be implemented for the respective targets as well as operational monitoring parameters that indicate whether the measure is working as it should.

Beyond their use for day-to-day operation, the data documented from operational monitoring of control measures can be highly valuable for system and risk assessment, as they may also indicate/validate how effectively a control measure is working. Documentation also supports the identification of trends over time and of conditions that may impact the efficacy of control measures (such as patterns of precipitation or drought).

Furthermore, a management plan should be developed which defines how the performance of key control measures is monitored and which corrective action should be taken if monitoring indicates poor performance, or if incidents occur (typically referred to as "operational monitoring plans", which may be part of standard operating procedures, SOPs). Operational monitoring plans for key control measures are important to ascertain their reliable performance at all times. These specify:

- Operational monitoring parameters for key control measures. An important criterion for the choice of the monitoring parameter is that it gives a result with sufficient time for taking corrective action before failure leads to cyanobacterial proliferation or cyanotoxin breakthrough and exposure.

- Documentation of data from operational monitoring: For each operational monitoring parameter, it is important to keep records of the monitoring data collected in order (i) to be able to trace what went 
wrong and why in cases of incidents or to validate that the system was working well even when excessively challenged, for example, by a bloom, (ii) to allow the recognition of trends in the data which may indicate a decline in the performance of the control measure (e.g., gradual reduction in filter runtimes at a water treatment plant over time may indicate that the filter media needs replacing) and (iii) to demonstrate due diligence in managing the system.

- Critical limits for each of the monitoring parameters that show operators when the system is "out of bounds" and corrective action needs to be taken on time.

- Corrective action(s) to take immediately in case monitoring shows a process to be outside of the critical limits, that is, performance criteria are not being met, including lines of responsibility and communication.

\subsubsection{Verifying that exposure is sufficiently avoided and water quality targets are achieved}

Verification in Water Safety Plan (WSP) terms refers to obtaining evidence that the WSP is working as whole to deliver safe drinking-water. In the context of toxic cyanobacteria, verification may involve:

- Compliance monitoring, that is, water quality testing to ensure that water quality objectives (e.g., national standards) are being achieved; this may be concentrations of the toxins themselves (e.g., against the guideline values given in Chapter 2 and Table 5.1 or prevailing national standards) or of cyanobacteria in the waterbody: if sufficiently frequent monitoring of cyanobacteria (or measures indicating their levels of biomass such as the concentration of chlorophyll- $a$ or even turbidity) shows that cyanobacteria are absent or only present at low concentrations, verification does not require monitoring toxin concentrations.

- WSP audits to ensure the WSP is up-to-date, is complete, is being implemented and is effective; depending on the local context, this may be carried out by internal or external bodies and may be a supportive assessment or more formal audit (which may or may not include penalties for noncompliance).

- Surveying user satisfaction may yield important information on, for example, taste/odour issues for drinking-water quality, observation of discoloration or odour/scum issues for recreational water use.

\subsubsection{Documenting the planning process and outcomes}

For an assessment as described above (whether or not it is conducted in the context of developing a WSP), it is important to document the considerations 
involved. This begins with a description of a water-use system. Maps of the catchment as well as water flow diagrams are useful not only for documentation, but also for understanding land-use patterns and how critical they are for the water budget and for nutrient loading. Flow diagrams can help conceptualise and visualise the points at which control can be exerted upon factors that affect cyanobacterial proliferation, toxin removal and water-use patterns. For each control measure, documentation should include the reasons for its choice and the targets it should achieve as well as how its adequacy for achieving the targets was validated. For control measures to be upgraded or newly implemented, documenting the rationale for such investments is important and provides reasoning for mobilising the necessary investments.

Documentation of the risk assessment and the criteria that led to its results is a necessary basis for successively further developing this assessment and for improving it. Therefore, this documentation should explicitly include information gaps and an assessment of how critical they are for making management decisions.

The target of documentation is a comprehensive overview rather than an extensive document. Where more in-depth information is needed, the overview best refers to further in-depth documents, like records of operational monitoring data.

\subsubsection{Documenting management procedures}

Management procedures should include the documentation of how to perform key operational activities (including operation of control measures) for normal operating conditions and incidents, as well as for emergency situations. For normal operating conditions and incidents, particularly for key control measures, typically this may take the form of SOPs (standard operating procedures), for example, day-to-day operation and monitoring of a water treatment filter, and what to do in an incident situation when this control measure fails. For these control measures, the level of detail useful in documentation will vary between settings. In general, such documents should be concise and readily available (including to technical staff). General experience is that after initial reluctance to document SOPs, they are found to be highly useful, particularly for maintaining "institutional memory", for keeping information accessible and for training new staff.

For emergency situations, emergency response plans should be developed (see also Chapter 15). They typically include the following example information:

- triggers for activating emergency response (e.g., detection of cyanotoxin levels above guideline values or prevailing national standards, or threshold values as given in the Alert Levels Frameworks in sections 5.1 and 5.2); 
- steps to protect water quality/public health (e.g., initiate pretreatment step; issue "do not drink" advisory and provision of alternative water supplies; issue "do not swim/fish" advisory);

- general roles and responsibilities (both within the water supply or waterbody management entity as well as external stakeholders);

- communication protocols (internal to the management entity and external, for example, to stakeholders such as users, regulators, health authorities, environmental agencies, recreational groups, community groups);

- in the case of drinking-water, alternative/emergency drinking-water supplies (e.g., emergency provision of bottled water, water tankers and public collection points).

\subsubsection{Developing supporting programmes}

Supporting programmes are actions that contribute to drinking-water safety but do not directly affect water quality. Such programmes can develop capacity (e.g., water treatment plant operator training), can strengthen relationships (outreach and awareness raising for recreational user groups), and can create enthusiasm and buy-in to the process from key stakeholders. Figure 6.3 shows examples of supporting programmes relevant to cyanobacterial management.

\subsubsection{Periodic review and revision}

Land uses and population densities in catchments undergo change, resulting in changes in the nutrient load to the waterbody. The climate is changing, resulting in changes in hydrodynamics, precipitation and seasonal patterns

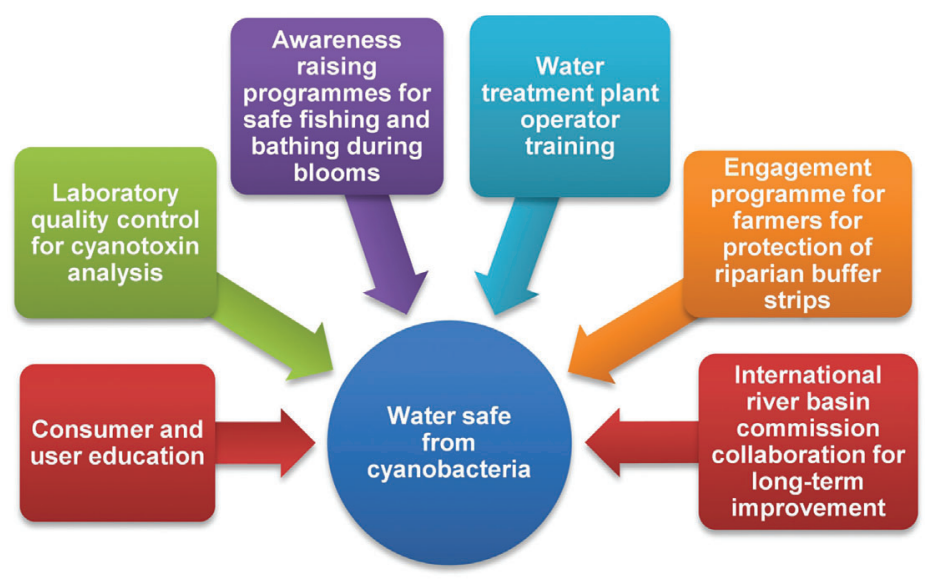

Figure 6.3 Examples of programmes to support the management of cyanotoxins in water-use systems. 
of thermal stratification. Such changes may significantly shift phytoplankton species occurrence and lead to increases or decreases in cyanobacterial blooms. Also, conditions in drinking-water treatment plants undergo changes. Therefore, periodic revision is necessary to ensure that the assessments and measures are still appropriate. It is additionally important to incrementally improve the WSP, incorporating experience gained as well as further expertise, capacities and resources. Revision is also recommended after incidents/near-misses to document key lessons learned which may inform the review and strengthen key aspects of the plan: for example, a heavy cyanobacterial bloom is a useful opportunity to study whether the control measures in place have proven valid even in an extreme event, or whether an upgrade is advisable, or if the emergency response plans implemented were effective in protecting human exposure.

\section{REFERENCES}

Bartram J, Correales L, Davison A, Deere D, Drury D, Gordon B et al. (2009). Water safety plan manual: step-by-step risk management for drinking-water suppliers. Geneva: World Health Organization:103 pp. https://apps.who.int/iris/ handle/10665/75141

Rickert B, Chorus I, Schmoll O (2016). Protecting surface water for health. Identifying, assessing and managing drinking-water quality risks in surface-water catchments. Geneva: World Health Organization:178 pp. https://apps.who.int/iris/ handle/10665/246196

WHO (2003). Guidelines for safe recreational water environments. Vol. 1: Coastal and fresh waters. Geneva: World Health Organization:251 pp. https://apps. who.int/iris/handle/10665/42591

WHO (2012). Water safety planning for small community water supplies: step-bystep risk management guidance for drinking-water supplies in small communities. Geneva: World Health Organization:55 pp. https://apps.who.int/iris/ handle/10665/75145

WHO (2017). Guidelines for drinking-water quality, fourth edition, incorporating the 1st addendum. Geneva: World Health Organization:631 pp. https://www. who.int/publications/i/item/9789241549950 